\title{
Stabilometric Characteristics of the Skateboarding Athlete from the Romberg Test
}

\author{
Carlos A Castillo-Daza ${ }^{1, *}$, Jhonatan C Peña-Ibagon ${ }^{1}$, Luis Eduardo Rodríguez Cheu ${ }^{2}$ \\ ${ }^{1}$ IMED Research Group, Biomechanics Laboratory, Sports Training Program, School of Health and Sport Sciences, \\ Fundación Universitaria del Área Andina, Bogotá, Colombia \\ ${ }^{2}$ GIBIOME Research Group, Biomedical Engineering Program, Escuela Colombiana de Ingeniería Julio Garabito, Bogotá, Colombia
}

Received July 7, 2021; Revised September 13, 2021; Accepted October 17, 2021

\section{Cite This Paper in the following Citation Styles}

(a): [1] Carlos A Castillo-Daza, Jhonatan C Peña-Ibagon, Luis Eduardo Rodríguez Cheu, "Stabilometric Characteristics of the Skateboarding Athlete from the Romberg Test," International Journal of Human Movement and Sports Sciences, Vol. 9, No. 6, pp. 1284 - 1290, 2021. DOI: 10.13189/saj.2021.090623.

(b): Carlos A Castillo-Daza, Jhonatan C Peña-Ibagon, Luis Eduardo Rodríguez Cheu (2021). Stabilometric Characteristics of the Skateboarding Athlete from the Romberg Test. International Journal of Human Movement and Sports Sciences, 9(6), 1284 - 1290. DOI: 10.13189/saj.2021.090623.

Copyright $\mathrm{C} 2021$ by authors, all rights reserved. Authors agree that this article remains permanently open access under the terms of the Creative Commons Attribution License 4.0 International License

\begin{abstract}
This research aims to find the characteristics of motor control at the level of body stability in skateboarding athletes from the city of Bogotá through a Romberg test with eyes open and eyes closed. The present study is of a descriptive cross-sectional type and the sample selection for the development of this research was for convenience, for which a direct invitation was performed at different skateboarding clubs in the city and the league skating Bogotá who supports the sport. The sample population corresponds to 30 people with an age between $22.86+/-7.88$ years. Participants developed Romberg test with a duration of $30 \mathrm{~s}$ and under the modalities eyes open and closed on a platform of plantar pressure and stabilometry BTS P-Walk. Significant changes were found in comparison of the open and closed eyes tests in the lateral flexion of the spine (LSF) with $\mathrm{p}=0.018$, body center of gravity with $\mathrm{p}=0.043$, left center of gravity with $\mathrm{p}=0.018$, showing improvements in body stability evaluation with eyes closed. It is evident that skateboarding athletes due to the dynamics and sports development on an unstable base present a high level of stability represented in mediolateral and anteroposterior stability and variability radii close to zero, additionally it is observed that work at eye level closed generates a better sports adaptation from the vestibular and peripheral system for motor control and balance.
\end{abstract}

Keywords Skateboarding, Body Stability, Balance, Romberg Test

\section{Introduction}

Skateboarding is a sport that is based on propulsion on a skateboard, which is composed of a high resistance pressed board, axles, bearings, and wheels, which allow the athlete's mobility on it for the development of maneuverability tricks. On the surface of wood, one sanded surface which increases the friction between footwear of the athlete and the table to improve grip and additionally to perform movements to complete the stunts in the development of competition it is located [1].

In 2017, the international Olympic committee decided to include skateboarding as an Olympic discipline and approved its first participation in the Olympic games to be held in Tokyo 2021 [2].

A level Colombia discipline is supported by the Colombian Federation of Skating (FEDEPATIN), and currently has a participation of 134 athletes at the national level to develop participation at professional level. (Colombian Skating Federation, 2018). But at the amateur level, this figure is higher since cities like Bogotá and neighboring municipalities have 12 district parks for free skateboarding [3].

The development of the sport consists of two modes, street, and park. In the first modality, street, recreates the elements that exist in an urban cone and there the athletes 
must perform their best acrobatics, from tricks that have well-known names in the community, such as grinds, slides, ollies, among others, which they are jumps and maneuvers with the skateboard using elements such as benches, handrails, and railings, among others. While in the park mode, athletes develop the dynamics of the discipline through maneuvers and acrobatics on ramps [4].

To obtain a passing score and reduce the risk of injury, one must have a balanced body behavior on unstable bases, develop good stability and have an adequate development of proprioceptive pathways that are responsible for the sense of one's own position and movement through the somatic senses that involve sensory information through the peripheral nervous system such as hearing, sight, taste, smell, and touch [5].

Stability and balance is classified in a dynamic and static way and is directly articulated with the type of movement developed, the balance of the body and the forces that interact to achieve the Balance [6].

The factors that influence the stability of skateboarding correspond to the balance and plantar pressures on the skateboard, which are related to the physical condition of the athlete and the characteristics at the kinetic level that allow a rapid adaptation to the athlete within the development of the sport to increase a base of support (BDS), lower the center of gravity and improve performance at the stability level [7]. At the kinetic level, it is necessary to emphasize that the human body in a bipedal or monopodal support position fundamentally regulates the stability of its balance through the intervention of the hip and ankle muscles, while the knee tends to remain semi-locked [8]. On the other hand, movement control occurs thanks to the integration of proprioceptive pathways, causing reflexes that are translated into muscular responses transmitted through mechano receptors to each body segment, which are important for detecting joint movements and positions especially in skateboarding where a higher level of coordination is required [9].

The stabilometric evaluation protocols are based on the analysis through platforms of forces or pressures that allow the subject to be in a safe bipedal position and that do not interfere with the oscillating movements of the center of gravity [9]. These protocols are usually developed in monopodal or bipodal support, in a strictly standardized position and that for skateboarding athletes represents a familiar position due to the location on the skateboard.

Between the years of 1840 and 1846, Romberg published the book "Lehrbuch der Nervenkrankheiten des Menschen", in this book the first bases of stability analysis are raised where the author suggests that if the patient is told to close his eyes while he remains upright, it immediately begins to move from side to side, and the oscillations cause it to lose its balance causing it to lose stability and fall to the ground. The person's eyes act on their balance control; therefore, in the absence of this sense the lack of control increases [10]. Additionally, he argues that central postural control depends on the impulses coming from three peripheral sensibility modalities: the visual, the vestibular system and the proprioception, the latter refers to the exact position of the parts of the body; the shape, size, and weight of objects, as well as the range and direction of joint movement. The posterior functions of the spinal cord are responsible for conducting the impulses of proprioception, discriminative touch, pressure, and vibration of the extremities to the brain nerve centers (brain stem, thalamus, and cortex) for the maintenance of coordination. At the ask the patient to close his eyes, proprioceptive any alteration that could be offset by the vision unmasks [11].

The main feature of the test is that allows athletes to access a complex test posture (balance) that is three peripheral modalities that are vision, vestibular apparatus, and proprioception (sense and joint position sense), and that this allows us that the athlete enters relationship and knowledge of the clinical test. In Skateboarding this type of test allows us to understand the capacity for coordination and balance based on the dynamics of the sport on an unstable basis and adaptation to changes in the position of the balance shafts [12].

The analysis of stability in skateboarding allows to analyze and characterize the motor component at the balance level that allows developing focused training plans and establishing risk analysis for the prevention of injuries, based on the fact that this sport discipline, which has a very prolonged difficulty due to the dynamics of each trick and work with obstacles [13]. A review in the United States presented that the most frequent injuries in medical care rooms in athletes of this discipline correspond to head trauma that represent between $3.5 \%$ to $13.1 \%$, injuries in the upper extremities between $5.5 \%$ to $6.3 \%$, thoracoabdominal injuries and of the spine with an incidence of $1.5 \%$ to $2.9 \%$ and lower extremity injuries that occur between $17 \%$ to $26 \%$ and a fatal injury rate corresponding to $1.1 \%$ [14].

Based on the above information, this article presents the characteristics of motor control at the level of body stability in skateboarding athletes from the city of Bogotá through a Romberg test with eyes open and eyes closed.

\section{Materials and Methods}

\subsection{Population}

The present study is of a descriptive cross-sectional type and the selection of the sample for the development of this research was carried out through a direct invitation to participate in the project to the different skateboarding clubs of the city and to the Bogotá skating league, which endorses the discipline of skateboarding. 
The sample population of this study are athletes who practice skateboarding in the city of Bogotá and for the purposes of this work correspond to a sample of 30 people.

The inclusion criteria for this project are the following:

- Women and men over 15 and under 30 .

- At least 2 years of experience in the sport of skateboarding.

- Acceptance of informed consent by parents for minors and by the participant when the athlete is over 18 years of age.

The exclusion criteria that will be considered correspond to:

- Lesions at the musculoskeletal level less than 1 year.

- Inappropriate sports accessory when taking measurements.

\subsection{Materials}

For the evaluation of the athletes, a pressure platform BTS BIOENGINEERING model P-Walk was used, which allows to measure the plantar pressure in static and dynamic phase, provides quantitative information on the plantar support calculating parameters such as surface, maximum pressure, pressure mean and center of pressure. The platform is made up of a mesh of 3,000 resistive sensors with a dimension of $1 \times 1 \mathrm{~cm}$, an acquisition frequency of $100 \mathrm{~Hz}$ and a pressure range of 30 to 400 $\mathrm{KPa}$. The data acquisition was developed through the G-Studio by means of a USB connection with the pressure platform.

Three measurements were made, considering for the analysis the average of the three measured signals, to reduce the error during capture. During each measurement carried out, a period of approximately 30 seconds was intentionally left for data processing, where the subject performed a march outside the measurement platform, in this way, the alteration of the measurements by reinforcement and adaptation of the patient to the test [15].

As a protocol, the Romberg test was implemented following the following process:

- The athlete was placed on the pressure platform in an anatomical position with a distance between the inner edges of the feet of $10 \mathrm{~cm}$.

- A target shooting was located to eye level and asked the athlete to observe the central red dot during the development of the entire test, a position that allows the vestibular system and somatosensory interacts with body balance helping to keep your position.

- The stability data was captured for $30 \mathrm{~s}$, guaranteeing the absence of noise and distractions.

- The athlete was asked to walk continuously for about 2 minutes, recover from the effort and return to the position shown in point 1 .

- The athlete was instructed to close his eyes and the capture was made again for 30 seconds. In this condition, the subject's visual perception is inhibited, thereby evaluating the other sensory systems that participate in balance.

\subsection{Ethical Considerations}

This research was endorsed by the ethics committee of the Fundación Universitaria del Área Andina under Act 0620 of April 21, 2020, which approved the protocol for measuring athletes in which risk management is contemplated and benefits of each of the participants in accordance with the Declaration of Helsinki and the governmental regulations of the Colombian state.

\subsection{Statistical Analysis}

For the analysis of the results obtained, the descriptive statistics data were organized by means of the means and standard deviation, normality tests were performed through the Shapiro-Wilk Test, finding a parametric distribution, due to this a test was performed the paired t-test for a $95 \%$ confidence interval $(\alpha=0.05)$, and the power of the effect was established by means of the d-Cohen.

To determine the characteristic equation of the stability behavior of the body center of gravity, a multiple linear regression was performed with an R2 of 0.754 and the statistic $F=41.3$ with a prediction significance $\rho<0.001[\mathrm{~F}$ $(2,54)=41.3, \rho<0.001]$.

\section{Results}

Table 1 shows the physical characteristics of the evaluated athletes and Table 2 shows the relationship of the type of the foot according to the data obtained from the plantar pressure measurements.

Table 1. Physical characteristics of the study population

\begin{tabular}{ccccc}
\hline Variable & Mean & $\begin{array}{c}\text { Standard } \\
\text { Deviation }\end{array}$ & Min & Max \\
\hline Age (years) & 22.9 & 4.14 & 18 & 37 \\
\hline Weight (Kg) & 59.9 & 9.635 & 40 & 87 \\
\hline Height (cm) & 168.23 & 8.496 & 149 & 183 \\
\hline $\begin{array}{c}\text { \% Right Static } \\
\text { Support }\end{array}$ & 42.32 & 7.17 & 23.2 & 56.8 \\
\hline \% Left Static Support & 57.67 & 7.17 & 43.2 & 76.8 \\
\hline Table 2. & Description of Foot Typology & \\
\hline $\begin{array}{c}\text { Foot Laterality / } \\
\text { Foot Type }\end{array}$ & $\begin{array}{c}\text { Cavus } \\
\text { Foot }\end{array}$ & Normal Foot & Total \\
\hline Right & 21 & 9 & 30 \\
\hline Left & 21 & 9 & 30 \\
\hline
\end{tabular}

From the Romberg test developed under the Open Eyes and Closed Eyes modality in the Table 3 shows the results obtained from the measurements of the displacements of the pressure centers and the center of gravity. The statistical results through the student $\mathrm{t}$-tests for related samples. 
Table 3. Body Stability Results

\begin{tabular}{|c|c|c|c|c|c|c|c|}
\hline Variable & Type of Test & Mean & $\begin{array}{c}\text { Standard } \\
\text { Deviation }\end{array}$ & Min & $\operatorname{Max}$ & $\rho$-Value & d-Cohen \\
\hline \multirow{2}{*}{ Mean COP Mid Lateral (mm) } & $\mathrm{OA}$ & 1.363 & 1.162 & -1.3 & 4.3 & \multirow{2}{*}{0.459} & \multirow{2}{*}{0.015} \\
\hline & $\mathrm{OC}$ & 1.357 & 1.339 & -1 & 4.6 & & \\
\hline \multirow{2}{*}{ Mean COP Anteroposterior (mm) } & $\mathrm{OA}$ & -2.683 & 2.343 & -7.6 & 3.4 & \multirow{2}{*}{0.866} & \multirow{2}{*}{0.156} \\
\hline & $\mathrm{OC}$ & -3.007 & 2.043 & -6.6 & 1.5 & & \\
\hline \multirow{2}{*}{ Variability COP Mid Lateral (mm) } & $\mathrm{OA}$ & 1.827 & 1.694 & 0.363 & 9.38 & \multirow{2}{*}{0.267} & \multirow{2}{*}{0.132} \\
\hline & $\mathrm{OC}$ & 1.445 & 0.914 & 0.461 & 4.04 & & \\
\hline \multirow{2}{*}{ Variability COP Anteroposterior (mm) } & $\mathrm{OA}$ & 3.805 & 3.021 & 0.995 & 12.56 & \multirow{2}{*}{$0.005^{*}$} & \multirow{2}{*}{$0.523 * *$} \\
\hline & $\mathrm{OC}$ & 2.421 & 1.41 & 0.366 & 5.488 & & \\
\hline \multirow{2}{*}{ Length COP (mm) } & $\mathrm{OA}$ & 228.607 & 85.676 & 90 & 477.2 & \multirow{2}{*}{0.380} & \multirow{2}{*}{0.024} \\
\hline & $\mathrm{OC}$ & 223.237 & 66.383 & 128.2 & 410.3 & & \\
\hline \multirow{2}{*}{ Mean Velocity (mm/s) } & OA & 9.993 & 3.121 & 4.5 & 17.2 & \multirow{2}{*}{0.688} & \multirow{2}{*}{0.004} \\
\hline & $\mathrm{OC}$ & 9.97 & 3.145 & 4.3 & 17.5 & & \\
\hline \multirow{2}{*}{$\mathrm{LSF}\left(\mathrm{mm} / \mathrm{mm}^{2}\right)$} & $\mathrm{OA}$ & 9.127 & 9.386 & 1.3 & 39.5 & \multirow{2}{*}{$0.034 *$} & \multirow{2}{*}{$0.586^{* *}$} \\
\hline & $\mathrm{OC}$ & 4.723 & 3.991 & 0.2 & 17 & & \\
\hline \multirow{2}{*}{ Left Foot Center Area $\left(\mathrm{mm}^{2}\right)$} & $\mathrm{OA}$ & 21.462 & 33.334 & 1.95 & 180.34 & \multirow{2}{*}{$0.018^{*}$} & \multirow{2}{*}{0.414} \\
\hline & $\mathrm{OC}$ & 9.896 & 10.143 & 0.75 & 40.55 & & \\
\hline \multirow{2}{*}{ Body Barycenter Area $\left(\mathrm{mm}^{2}\right)$} & $\mathrm{OA}$ & 129.877 & 279.968 & 13.44 & 1574.4 & \multirow{2}{*}{$0.043 *$} & \multirow{2}{*}{0.396} \\
\hline & $\mathrm{OC}$ & 56.996 & 52.077 & 5.99 & 187.67 & & \\
\hline \multirow{2}{*}{ Right Foot Center Area $\left(\mathrm{mm}^{2}\right)$} & $\mathrm{OA}$ & 55.773 & 204.969 & 2.4 & 1135.05 & \multirow{2}{*}{0.128} & \multirow{2}{*}{0.181} \\
\hline & $\mathrm{OC}$ & 14.988 & 17.446 & 1.19 & 56.1 & & \\
\hline
\end{tabular}

* Represent statistically significant differences

** Represent medium size effect for the d-Cohen

When analyzing the descriptive results at the level of stability and assuming that this is directly related to the mediolateral and anteroposterior variability and these with the areas of the center of gravity and that the smaller a body is, the more stable, it can be observed that according to the dynamics of sports discipline and work on an unstable base have median lateral variabilities on average of $1.82 \mathrm{~mm}$ and anteroposterior variabilities of $3.8 \mathrm{~mm}$ during the evaluation with eyes open and that this behavior improves during development with eyes closed, allowing evidence that the development of sports practice generates a response from the motor control and at the vestibular level to avoid loss of balance in the absence of visual stimulus, allowing to obtain significant changes in anteroposterior variability, in the projection of lateral spinal flexion (LSF) and in the body center of gravity.

The effect analysis developed through the d-Cohen allows to establish that the significant changes found for the variables LSF, Anteroposterior Variability COP have a difference effect between the closed and open eyes tests, allowing to determine that the changes found are the product of the control of the vestibular system and not as a compensative balance strategy.

In order to evaluate the behavior of the body center of gravity from the variables medial lateral variability, anteroposterior variability, LSF, mean speed and COP distance, a multiple linear regression model was proposed with an R2 of 0.754 and the statistic $F=41.3$ with a prediction significance $\rho<0.001[\mathrm{~F}(2,54)=41.3, \rho$ $<0.001]$.

Within the linear regression model, a backward stepwise data entry method was used, finding that the behavior of the body's center of gravity is determined by the equation 1 :

$$
\begin{array}{r}
B B A=-44.442+(33.97 * V C O P M L)+ \\
(8.949 * V C O P A P)+(4.522 * M V)-(1.469 * L S F)
\end{array}
$$

$\mathrm{BBA}=$ Body Barycenter Area

$\mathrm{V}$ COP $\mathrm{ML}=$ Variability COP Mid Lateral

$\mathrm{V}$ COP AP $=$ Variability COP Anteroposterior

$\mathrm{MV}=$ Mean Velocity

$\mathrm{LSF}=$ Lateral Spine Flexion

\section{Discussion}

Skateboarding began its Olympic participation in Tokyo 2020, during the Olympic games held in 2021 due to the restrictions given by the COVID-19 pandemic, the biomechanical studies developed in this sport discipline focus on the analysis of forces during take-off and landing. However, the development of research and analysis at the 
level of body balance has not been deepened in this sport discipline. Studies in the analysis of balance and postural motor control that allow the biomechanical analysis of athletes in this discipline are necessary and fundamental. These studies allow focusing training plans to reduce the risk of injury, develop sports optimizations and establish comparisons with other disciplines.

When analyzing the results, a greater body stability is observed in the test developed with eyes closed compared to the test with eyes open, this behavior is reflected in the decrease in the values of the averages of the area centers of the right and left feet, and body, additionally, a decrease in the averages of the LSF is observed, which represents the compensatory movements of the Core when there is a loss of stability.

Pinzón-Romero, SM. present a study in 2018 where they analyze a training plan to improve balance through proprioceptive activities in skaters, considering that skating requires the athlete to adapt their body to a particular and unnatural movement, in which the fulcrum is reduced. Consequently, its support is based on four fixed wheels in a line that slide on a surface and draw a straight line obliquely to advance; This condition produces continuous changes in balance and, therefore, causes a greater degree of instability compared to other sports. Precisely, balance is the fundamental component in skating because it allows to maintain an adequate technique and control in the execution of each sporting gesture and, in addition, it limits accessory movements that increase joint stress. Proper roller-skating technique is based on achieving maximum effectiveness and efficiency of the forces applied to the skate during the pushing, sliding and recovery phases. The development research allows to show that the work on the board, which can be constituted as an unstable base, allows improving the proprioceptive conditions in skateboarding athletes [16].

According to Varszegi et al, 2016, the dynamics of the movement given in skateboarding generates that as speed increases, body stability increases, based on this premise and that the dynamics of the sport is based on the development of figures and given points. Due to rapid movements, the daily practice of this sport generates an increase and improvement in body stability [17].

Additionally, the results obtained regarding the motor control required at the stabilometric level and that is given by the vestibular system correlate with the behavior and the silver model by Hubbard in 1980, from which the author presents that the stabilometric work of skateboarding is related with the behavior of a rigid body on an unstable base and which is regulated by the feedback phases given by the movement of the center of gravity that the correction of this generates in the athlete to avoid falling, this set of response stimuli generates a training of the proprioceptive and vestibular system that represents the improvements found in the test with eyes closed[18].
Taking into account the work developed by C. Cifuentes-De la Portilla, et al., Entitled "Reference biomechanical patterns for the early diagnosis of balance disorders: Pilot study", in which 38 participants were evaluated between 18 and 22 healthy years, through the Romberg test by means of a force platform, they found that the results in the test with open eyes of medial lateral stability corresponded to $7.153 \mathrm{~mm} \pm 3.4$ and at the anteroposterior level $7.853 \mathrm{~mm} \pm 3.1$ while in the test with closed eyes reported a medial lateral stability corresponding to $10,151 \mathrm{~mm} \pm 4.2$ and anteroposterior level $9,499 \mathrm{~mm} \pm 4.4$, it can be seen that the results found in the present study show much higher stability values both in the test with open eyes and in the closed eyes test, which correspond to medial lateral stability of $1,363 \mathrm{~mm}$ $\pm 1,162$ and anteroposterior level 2,683 $\mathrm{mm} \pm 2,343$ for the test with eyes open and a medial lateral stability of $1,357 \mathrm{~mm} \pm 1,339$ and at the anteroposterior level 3,007 $\mathrm{mm} \pm 2,343$ for the test with closed eyes [19].

On the other hand, the study developed by Shirabe N. et al., Entitled "Taekwondo athletes have better postural control than handball and American football athletes" the authors present an analysis of the areas of the center of gravity of the left and right foot in 10 athletes of taekwondo, handball and American football aged between 18 and 26 years through a bipodal test with eyes open. The authors report that for taekwondo the center of gravity of the right foot corresponds on average to 600 $\mathrm{mm}^{2}$, while for the left it corresponds on average to 700 $\mathrm{mm}^{2}$; for Handball, the center of gravity of the right foot corresponds on average to $1100 \mathrm{~mm}^{2}$, while for the left it corresponds to an average of $1100 \mathrm{~mm}^{2}$ and for American football the center of gravity of the right foot corresponds to an average of $1100 \mathrm{~mm}^{2}$, while for the left it corresponds to average at $1100 \mathrm{~mm}^{2}$; In the present study, a better stabilometric performance is observed in the areas of the right center of gravity, with a record of $55 \mathrm{~mm}^{2}$ on average and for the left foot of $21 \mathrm{~mm}^{2}$. These results are due to greater motor control at the stabilometric level given by constantly working on the unstable base represented by the skateboard, the duration of sports practice per day and the dynamics of the sport [20].

It is recommended to propose comparisons between different sports disciplines at the national level since the studies that served as the basis for the comparison of results were developed in Europe, additionally the possibility of evaluating the improvements in this discipline through intervention by science professionals is proposed of sport on athletes of this discipline and more at this time that it was endorsed by the International Olympic Committee as an Olympic discipline.

Based on the results obtained at the level of body stability, it is recommended to develop studies of different stability exercises for skateboarding as a proprioceptive training system at the rehabilitation level and at the sports level for other disciplines. 


\section{Conclusions}

Skateboarding athletes have stability levels close to zero because constant work on an unstable and dynamic base requires a sports adaptation to avoid falls and develop the dynamics of the sport.

The dynamics of the sport of skateboarding and working on an unstable base during its development generates a profile of stability and balance that is evident during the development of the stability tests with eyes open and eyes closed. Additionally, the feedback dynamics given by the need for balance shows a control at the vestibular and corporal level that is evidenced in the best stability obtained during the execution of the test with eyes closed.

The use of unstable base bases, such as the skateboard in this case, allows the development of improvements at the proprioceptive level, which requires the development of specific training plans in this area to improve the sports conditions of the athletes of this discipline.

\section{Conflict of Interest}

The authors declare that they have no competing interests.

\section{REFERENCES}

[1] Federación Madrileña de Patinaje, "¿Qué es el skateboarding? - Federación Madrileña Patinaje," 2018. http://www.fmp.es/que-es-el-skateboarding/ (accessed Dec. $16,2019)$

[2] EcuRed, "Skateboarding - EcuRed," 2018.https://www.ecu red.cu/Skateboarding (accessed Dec. 16, 2019).

[3] Skatecol, "SKATE MAP Bogotá.” http://www.skatecol.co m/index.php/icons/bogota (accessed Apr. 04, 2019).

[4] C. Lawrence, "Skateboard Tricks | HowStuffWorks," 2019. https://entertainment.howstuffworks.com/skateboarding3.h tm (accessed Dec. 18, 2019).

[5] A. Lluch, G. Salvà, M. Esplugas, M. Llusá, E. Hagert, and M. Garcia-Elias, "El papel de la propiocepción y el control neuromuscular en las inestabilidades del carpo," Rev. Iberoam. Cirugía la Mano, vol. 43, no. 01, pp. 070-078, May 2015, doi: 10.1016/j.ricma.2015.06.012.

[6] C. A. Yanez, C. Castillo, J. Peña, and J. Granado, "The relationship between open and closed eyes in static balance in elderly adult women before and after aerobic dance training program,” J. Am. Geriatr. Soc., vol. 67, no. S1, pp. S1-S384, Apr. 2019, doi: 10.1111/jgs. 15898.

[7] D. R. Bell, K. M. Guskiewicz, M. A. Clark, and D. A. Padua, "Systematic review of the balance error scoring system," Sports Health, vol. 3, no. 3. Sports Health, pp. 287-295, May 2011, doi: 10.1177/1941738111403122.
[8] D. A. Winter, Biomechanics and Motor Control of Human Movement, Fourth Edition David A. Winter (cloth) 1. Human mechanics. 2. Motor ability. 3. Kinesiology. I. Title. QP303.W59, vol. 7. 2009.

[9] P. Optar Por El, T. Profesional, M. Arakaki Villavicencio, J. Miguel, and A. Lima -Perú, "ENTRENAMIENTO PROPIOCEPTIVO EN TERAPIA FÍSICA Trabajo de Suficiencia Profesional Macalupu More, Irene Rocío," Universidad Inca Garcilaso de la Vega, Jan. 2018. Accessed: Jun. 03, 2021. [Online]. Available: http://repositorio.uigv.edu.pe/handle/20.500.11818/4918.

[10] F. O. Black, C. Wall, H. E. Rockette, and R. Kitch, "Normal subject postural sway during the romberg test," Am. J. Otolaryngol. Neck Med. Surg., vol. 3, no. 5, pp. 309-318, 1982, doi: 10.1016/S0196-0709(82)80002-1.

[11] P. de Romberg, L. prueba de Romberg Moritz Heinrich Romberg The Romberg test, M. Heinrich Romberg García-Pastor Cuauhtémoc, and Á.-S. Gabriela Alejandra, “García-Pastor C, et al." Accessed: Jun. 04, 2019. [Online]. Available:http://revmexneuroci.com/wp-content/uploads/2 014/05/Nm141-05.pdf.

[12] M. J. Major, A. J. Beaudoin, P. Kurath, and E. T. Hsiao-Wecksler, "Biomechanics of aggressive inline skating: Landing and balancing on a grind rail," J. Sports Sci., vol. 25 , no. 12 , pp. 1411-1422, Oct. 2007, doi: $10.1080 / 02640410601129615$.

[13] F. Feletti and E. Brymer, "Pediatric and adolescent injury in skateboarding," Res. Sport. Med., vol. 26, no. sup1, pp. 129-149, Apr. 2018, doi: 10.1080/15438627.2018.143828 5.

[14] K. M. Shuman and M. C. Meyers, "Skateboarding injuries: An updated review," Phys. Sportsmed., vol. 43, no. 3, pp. 317-323, Jul. 2015, doi: 10.1080/00913847.2015.1050953.

[15] F. B. Horak, "Postural Control," in Encyclopedia of Neuroscience, Springer Berlin Heidelberg, 2008, pp. 32123219.

[16] Pinzón-Romero SM. Efectos De Un Programa De Ejercicio Físico Propioceptivo Sobre El Equilibrio En Jóvenes Patinadores Entre Los 11 A 15 Años Pertenecientes A La Liga Santandereana De Patinaje De Carreras En La Ciudad De Bucaramanga, 2016 [Internet]. [Manizalez] Universidad Autónoma de Manizales; 2017 [cited 2021 Aug 9]. Available from:http://repositorio.autonoma.edu.co /bitstream/11182/516/1/Efectos_programa_ejercicio_físico propioceptivo equilibrio jóvenes patinadores $11 \overline{1} 15$ añ os liga Santandereana patinaje carreras ciudad Bucara manga_2016.pdf.

[17] B. Varszegi, D. Takacs, and G. Stepan, "Skateboard: A Human Controlled Non-Holonomic System," in Volume 6: 11th International Conference on Multibody Systems, Nonlinear Dynamics, and Control, Aug. 2015, p. V006T10A066, doi: 10.1115/DETC2015-47512.

[18] M. Hubbard, "Human control of the skateboard," J. Biomech., vol. 13, no. 9, pp. 745-754, Jan. 1980, doi: 10.1016/0021-9290(80)90236-5.

[19] C. Cifuentes-De La Portilla, O. Perdomo-Charry, and R. Argothy-Bucheli, "Patrones biomecánicos de referencia para el diagnóstico temprano de trastornos del equilibrio: Estudio piloto," Rev. Mex. Ing. Biomed., vol. 38, no. 1, pp. 93-102, Jan. 2017, doi: 10.17488/RMIB.38.1.6. 
[20] N. A. Shirabe et al., "Atletas de taekwondo têm melhor controle postural do que atletas de handebol e futebol Americano," Rev. Bras. Med. do Esporte, vol. 23, no. 6, pp.
473-476, Nov. 2017, doi: 10.1590/1517-86922017230617 0049 . 